\title{
Influência do Período de Descanso da Pastagem de Capim-Elefante na Produção de Leite de Vacas Mestiças Holandês x Zebu
}

\section{Fermino Deresz ${ }^{1}$}

\begin{abstract}
RESUMO - O objetivo do experimento foi estudar o efeito de três períodos de descanso (T30 = 30 dias, T36 = 36 dias e T45 = 45 dias) sobre a produção de leite e variação de peso vivo de vacas mestiças Holandês x Zebu em pastagem de capim-elefante manejada em sistema rotativo. O experimento foi realizado durante a estação chuvosa, usando-se 18 vacas, tendo em média 30 dias de lactação e peso vivo médio de $488 \mathrm{~kg}$. As vacas foram distribuídas pelos tratamentos em seis blocos completos ao acaso, constituídos de duas séries de piquetes (repetição de área) e três vacas/piquete, formados com base na produção de leite e no peso vivo no início da lactação. A lotação foi de 4,5 vacas/ha para todos os tratamentos e as vacas não receberam concentrado. O período de ocupação dos piquetes foi de três dias. A pastagem foi adubada com $200 \mathrm{~kg} /$ ha de $\mathrm{N}$ e $\mathrm{K}_{2} \mathrm{O}$, divididos em três aplicações, durante a época das chuvas. Foram aplicados também $40 \mathrm{~kg}$ de $\mathrm{P}_{2} \mathrm{O}_{5}$ e $1 \mathrm{t}$ de calcário dolomítico, no início da época das chuvas. A produção média de leite corrigida para $4 \%$ de gordura foi de 11,4; 10,6; e 10,3 kg/vaca/dia e o ganho médio diário, de 114, 160 e 116 g para os tratamentos T30, T36 e T45, respectivamente. Não houve diferença entre os tratamentos para produção de leite, nem para ganho de peso.
\end{abstract}

Palavras-chave: capim-elefante, pastejo rotativo, período de descanso, peso vivo, produção de leite

\section{Effect of Grazing Interval for Elephantgrass Pastures on Milk Yield and Live Weight Changes of Crossbred Holstein x Zebu Cows}

\begin{abstract}
The objective of this trial was to study the effect of three grazing intervals (T30 = 30 days, T36 $=36$ days and $\mathrm{T} 45=45$ days) on milk yield and live weight changes of crossbred Holstein $\mathrm{x}$ Zebu cows grazing elephantgrass pasture rotationally managed. The experiment was conducted during the rainy season using 18 crossbred cows averaging 30 days of lactation and $488 \mathrm{~kg}$ of average live weight. The cows were allocated to experimental treatments according to a completely randomized block design, with six blocks, two series of paddocks and three cows/paddock, based on milk yield and body weight of cows at the beginning of lactation. The stocking rate was fixed at $4.5 \mathrm{cows} / \mathrm{ha}$ and no concentrate was fed. Each paddock was grazed for three days in each grazing cycle. The pasture was fertilized with $200 \mathrm{~kg} / \mathrm{ha}$ of $\mathrm{N}$ and $\mathrm{K}_{2} \mathrm{O}$, divided in three applications during the rainy season. It was also applied $40 \mathrm{~kg}$ of $\mathrm{P}_{2} \mathrm{O}_{5}$ and $1,000 \mathrm{~kg}$ of dolomite limestone at the same time of the first application of $\mathrm{N}$ and $\mathrm{K}$. The average fat corrected (4\%) milk yield was $11.4 ; 10.6$ and $10.3 \mathrm{~kg} / \mathrm{cow}$. day and the average liveweight gain during the experimental period was $114,160 \mathrm{and} 116 \mathrm{~g} / \mathrm{cow}$. day for the T30, T36 and T45 treatments, respectively. No difference was observed either for milk yield or liveweight gain.
\end{abstract}

Key Words: elephantgrass, grazing intervals, live weight, milk yield, rotational grazing

\section{Introdução}

O capim-elefante (Pennisetum purpureum, Schum.) é uma gramínea perene, de alto potencial de produção, adaptando-se às condições climáticas predominantes em quase todo o país. Entretanto, em muitas regiões, aproximadamente 70 a $80 \%$ da sua produção concentra-se na época das chuvas. Essa estacionalidade de produção de forragem é atribuída às baixas precipitações e temperaturas que ocorrem no período de inverno.

Durante a época das chuvas, DERESZ (1994) encontrou taxas diárias de acúmulo de matéria seca de capim-elefante de até $100 \mathrm{~kg} / \mathrm{ha}$ sob condições de pastejo. Produções de leite de $15.000 \mathrm{~kg} / \mathrm{ha} / 180$ dias durante a época das chuvas foram relatadas por DERESZ e MOZZER (1994), usando vacas mestiças Holandês x Zebu em pastejo rotativo de capimelefante. Produções diárias de leite de 12 a $14 \mathrm{~kg} /$ vaca, em pastagem de capim-elefante manejado em sistema rotativo e adubado com $200 \mathrm{~kg}$ de $\mathrm{N}$ e $\mathrm{K}_{2} \mathrm{O} / \mathrm{ha}$ /ano, foram observadas por DERESZ et al. (1994). Esses níveis de produção de leite em pastagem com forrageiras tropicais parecem estar próximos do limite máximo de produção obtidos com vacas mestiças de bom potencial genético e produções por lactação ao redor de $4500 \mathrm{~kg}$. COWAN et al. (1993), ALVIM et al. (1996) e VILELA et al. (1996), trabalhando 
com vacas da raça Holandesa, estimaram produções médias diárias bem próximas de 12 a $14 \mathrm{~kg}$ por dia, quando se descartou o efeito da suplementação do concentrado.

Atualmente, nota-se uma tendência para produção de leite a partir de pastagens, visando à diminuição dos custos de produção, devido, principalmente, ao elevado preço do concentrado. Na Nova Zelândia, HOLMES (1995) afirma que a produção de leite a pasto é o sistema mais econômico de se produzir leite. Ultimamente, existe grande demanda por informações sobre o uso do capim-elefante e outras gramíneas tropicais manejadas em sistema de pastejo rotativo para produção de leite e carne, visando principalmente à diminuição dos custos de produção.

O período de descanso é um fator importante no sistema de pastejo rotativo de capim-elefante e de outras forrageiras, pois determina: 1 - o rendimento forrageiro, 2 - o valor nutritivo da forragem, 3 - a perenidade da pastagem e 4 - o número de piquetes necessários ao seu manejo. O período de descanso afeta também a composição química da forragem e, conseqüentemente, a produção de leite (DERESZ, 1994; DERESZ et al., 1994). Em trabalho com capimelefante anão, VEIGA (1990) concluiu que a qualidade da forragem consumida era melhor nos períodos de descanso mais curtos que nos mais longos, em uma faixa variando de 14 a 56 dias. Não há trabalhos na literatura comparando o efeito do período de descanso sobre a produção de leite em pastagem de capimelefante de porte alto, a não ser aqueles realizados por DERESZ (1994) e DERESZ et al. (1994), os quais compararam o efeito do período de descanso em pastagem de capim-elefante de 30, 37,5 e 45 dias. As informações da literatura sobre o período de descanso em pastagem de capim-elefante na produção de leite de vacas mestiças Holandês x Zebu, realizados pela Embrapa Gado de Leite, mostram maior produção de leite para os tratamentos com período de descanso de 30 dias com relação a 45 dias. Entretanto, o sistema de manejo da pastagem adotado pela Embrapa Gado de Leite é de resíduo pós-pastejo na faixa de 80 a $100 \mathrm{~cm}$ de altura, enquanto o sistema de produção de leite da ESALQ, em Piracicaba-SP, adota 45 dias de período de descanso e altura de resíduo na faixa de 40 a $50 \mathrm{~cm}$, o que resulta em hierarquia e tipos diferentes de perfilho na planta. Essa é uma das razões de os resultados obtidos nestes sistemas serem conflitantes. Além disso, não há na literatura comparação entre estes dois sistemas manejados de forma semelhante para poder avaliar qual seria o melhor sistema a ser recomendado para as condições brasileiras e quais seriam as vantagens e desvantagens de cada sistema. As outras informações da literatura sobre o período de descanso em pastagem de capim-elefante referem-se a sistemas de produção com manejos distintos (HILLESHEIM, 1987; VALLE et al., 1987; CAROCOSTAS e VICENTE-CHANDLER, 1974).

A altura do resíduo pós-pastejo em capim-elefante e seu efeito na produção de forragem são pouco estudados na literatura. WERNER et al. (1966) observaram maior produção de matéria seca em capim-elefante cv. Napier, quando cortado a cada quatro semanas na altura de $70-80 \mathrm{~cm}$, em comparação a 30-40 cm. Resultados semelhantes foram encontrados por SANTANA et al. (1989), quando o capim foi cortado a cada quatro semanas nas alturas de corte de zero, 15 e $30 \mathrm{~cm}$ do solo. VEIGA (1990) também observou maior produção de matéria seca em capimelefante anão, quando a altura do resíduo foi maior, independente do período de descanso estudado. Entretanto, nestes trabalhos não se avaliou a resposta em termos de produção de leite.

O objetivo deste trabalho foi avaliar o efeito do período de descanso de uma pastagem de capimelefante, manejada em sistema rotativo, na produção de leite e variação de peso vivo de vacas mestiças Holandês x Zebu, sem suplementação de concentrado.

\section{Material e Métodos}

O experimento foi conduzido em uma área de pastagem exclusiva de capim-elefante, a qual vem sendo utilizada em pastejo rotativo desde 1988. Essa pastagem tem sido adubada anualmente durante a estação das chuvas com $200 \mathrm{~kg} / \mathrm{ha}$ de nitrogênio e de $\mathrm{K}_{2} \mathrm{O}$, os quais sempre foram fracionados em três aplicações iguais. Usualmente, a primeira aplicação era feita em novembro; a segunda, em janeiro; e a terceira, em março. Esta área não recebeu adubação na estação seca do ano nestes últimos seis anos.

Os tratamentos estudados foram: $\mathrm{T} 30=30$ dias de descanso da pastagem, T36 $=36$ dias de descanso da pastagem e T45 $=45$ dias de descanso da pastagem.

A pastagem foi dividida em piquetes e manejada em sistema rotativo da seguinte forma: o tratamento com período de descanso de 30 dias tinha 11 piquetes por repetição de área; o tratamento com 36 dias de período de descanso, 13 piquetes por repetição de área; e o tratamento com 45 dias, 16 piquetes por repetição de área. O tamanho dos piquetes variava entre os tratamentos, objetivando obter uma taxa de 
lotação de 4,5 vacas por hectare. Para se conseguir a mesma taxa de lotação entre os tratamentos, os piquetes tinham as seguintes áreas: 606, $513 \mathrm{e}$ $427 \mathrm{~m}^{2}$, para os períodos de descanso de 30, 36 e 45 dias, respectivamente. O período de ocupação dos piquetes foi de três dias, independente do tratamento e da disponibilidade de forragem.

Foram usadas 18 vacas mestiças Holandês $\mathrm{x}$ Zebu, de diferentes graus de sangue, sendo seis vacas por tratamento, com cerca de 30 a 40 dias pósparto. As vacas foram distribuídas pelos tratamentos em delineamento de blocos completos ao acaso, constituídos de duas séries de piquetes (repetição de área) com três vacas/piquete. Os blocos foram formados com base na produção de leite e no peso vivo das vacas, no período inicial de lactação.

Durante este experimento, a primeira aplicação de nitrogênio (uréia) e potássio (cloreto de potássio) foi feita no início de novembro de 1993 e distribuída na área toda. A segunda aplicação iniciou-se em 13/12/93 e foi feita gradualmente, sempre após a saída das vacas dos piquetes. A terceira aplicação iniciou-se em 13/01/94 e acabou no início de abril, também sempre após a saída das vacas dos piquetes. A aplicação do adubo foi feita sempre a lanço e quando havia boas condições de umidade do solo.

As aplicações de fósforo (superfosfato simples) e calcário dolomítico também foram feitas a lanço, no início da estação das chuvas, na base de $40 \mathrm{~kg} / \mathrm{ha}$ de $\mathrm{P}_{2} \mathrm{O}_{5}$ e $1000 \mathrm{~kg} / \mathrm{ha}$, respectivamente.

O solo foi classificado como sendo um Latossolo Vermelho-Amarelo, distrófico de textura argilosa e relevo variando de encosta a baixada. A análise química feita na estação seca de 1993 mostrou as seguintes características: $\mathrm{pH}$ em água $=4,70$; $\mathrm{P}=9,15 \mathrm{mg} / \mathrm{dm}^{3} ; \mathrm{K}=128 \mathrm{mg} / \mathrm{dm}^{3} ; \mathrm{Al}=0,16 \mathrm{cmolc} / \mathrm{dm}^{3}$; $\mathrm{Ca}=1,95 \mathrm{cmolc} / \mathrm{dm}^{3} ; \mathrm{Mg}=0,50 \mathrm{cmolc} / \mathrm{dm}^{3} ;$ $\mathrm{CTC}=9,42 \mathrm{cmolc} / \mathrm{dm}^{3}$ e $\mathrm{MO}=3,40 \mathrm{~g} / \mathrm{kg}$.

$\mathrm{O}$ trabalho foi implantado em uma área de pastagem de capim-elefante já estabelecida, então, para iniciar o trabalho; assim que as vacas foram parindo elas entravam no manejo dos piquetes, até completarem seis vacas/tratamento. Assim que as 18 vacas foram selecionadas teve início o experimento. Os piquetes de todos os tratamentos foram manejados para se obter uma altura de resíduo pós-pastejo em torno de $90-100 \mathrm{~cm}$. O estabelecimento da altura do resíduo, quando necessário, foi feito por meio de roçada manual, antes do início do trabalho e sempre que necessário, durante o período experimental, sempre logo após a saída das vacas do piquete.
A estimativa da disponibilidade de forragem foi feita mensalmente, um dia antes da entrada dos animais nos piquetes, pela metodologia do pastejo simulado, observando-se a altura do resíduo dos piquetes recém-desocupados. O pastejo simulado foi feito em touceiras representativas, com disponibilidade de forragem alta e baixa, em dois pontos diferentes e em cada repetição de área dos piquetes de cada tratamento. As folhas e caules provenientes da rebrota foram retirados para a estimativa da produção de forragem. A disponibilidade de forragem por hectare foi estimada por intemédio da produção média das duas touceiras e do número de touceiras contidas em uma área de $100 \mathrm{~m}^{2}$ de cada piquete. As amostras para análise química da forragem foram coletadas durante os três dias de ocupação do piquete, pelo método de extrusa utilizando-se animais extras canulados no esôfago e equipados com bolsas para a coleta das amostras de forragem, nos diferentes tratamentos nos meses de janeiro, março, abril e maio de 1994.

As vacas foram ordenhadas manualmente sem a presença do bezerro duas vezes ao dia, sendo a primeira ordenha das 6 às $8 \mathrm{~h} 30$ da manhã e a segunda, das 14 às $16 \mathrm{~h}$ da tarde. No horário das ordenhas, as vacas ficavam em currais separados por tratamento, onde tinham acesso à sombra, água e mistura mineral à vontade. Não havia bebedouros nem cochos de sal mineral nos piquetes, de maneira que as vacas tinham acesso à água apenas nos intervalos de ordenha.

As vacas foram pesadas semanalmente, sempre logo após a ordenha da manhã. A amostragem do leite para a determinação de gordura, proteína e extrato seco total foi feita semanalmente, em quantidades proporcionais à produção de leite da ordenha da tarde e da manhã, em frascos de plástico de $200 \mathrm{~mL}$ providos de dicromato de potássio.

Na Tabela 1, são mostrados os dados médios de precipitação e o número de dias de ocorrência de chuva, durante o período de 1980 a 1992, obtidos no posto meteorológico localizado a aproximadamente $1 \mathrm{~km}$ de distância do local do experimento.

Observa-se que a estação chuvosa usualmente se concentra de setembro a abril, contudo, os dados de precipitação dos meses de abril e setembro são inferiores a $100 \mathrm{~mm}$. Nota-se também que a distribuição de chuva neste período parece satisfatória, visto que o número de dias de ocorrência de chuva mensal foi superior a 11 (Tabela 1).

A coleta de dados começou em 24/11/93 e terminou em 08/06/94. 
Tabela 1 - Dados médios de precipitação $(\mathrm{mm})$ e número médio de dias de ocorrência de chuvas no período de 1980 a 1992

Table 1 - Monthly rainfall distribution $(\mathrm{mm})$ and number of rainy days from 1980 to 1992

\begin{tabular}{|c|c|c|}
\hline \multirow[t]{2}{*}{$\begin{array}{l}\text { Mês } \\
\text { Month }\end{array}$} & \multicolumn{2}{|c|}{$\begin{array}{l}\text { Período } 1980 \text { a } 1992 \\
\text { Period } 1980 \text { to } 1992\end{array}$} \\
\hline & $\begin{array}{c}\text { Precipitação }(\mathrm{mm}) \\
\text { Rainfall }\end{array}$ & $\begin{array}{c}\mathrm{N}^{\mathrm{o}} \text { dias } \\
\text { Rainy days }\end{array}$ \\
\hline $\begin{array}{l}\text { Jan. } \\
\text { Jan. }\end{array}$ & 381 & 19 \\
\hline & 194 & 12 \\
\hline $\begin{array}{l}\text { Mar. } \\
\text { Mar. }\end{array}$ & 220 & 14 \\
\hline $\begin{array}{l}\text { Abr. } \\
\text { Apr }\end{array}$ & 92 & 8 \\
\hline $\begin{array}{l}\text { Maio } \\
\text { May }\end{array}$ & 46 & 5 \\
\hline $\begin{array}{l}\text { Jun. } \\
\text { Jun. }\end{array}$ & 32 & 4 \\
\hline $\begin{array}{l}\text { Jul. } \\
\text { Jul. }\end{array}$ & 16 & 3 \\
\hline $\begin{array}{l}\text { Ago. } \\
\text { Aug. }\end{array}$ & 20 & 4 \\
\hline $\begin{array}{l}\text { Set. } \\
\text { Sep. }\end{array}$ & 91 & 8 \\
\hline $\begin{array}{l}\text { Out. } \\
\text { Oct. }\end{array}$ & 110 & 11 \\
\hline $\begin{array}{l}\text { Nov. } \\
\text { Nov. }\end{array}$ & 200 & 14 \\
\hline $\begin{array}{l}\text { Dez. } \\
\text { Dec. }\end{array}$ & 291 & 19 \\
\hline
\end{tabular}

\section{Resultados e Discussão}

Na Tabela 2, são apresentados o número de ciclos completos de pastejo realizados para cada período de descanso estudado durante o período experimental. Observa-se que, no descanso de 30 dias, a pastagem foi utilizada por seis ciclos completos e no de 45 dias, por apenas quatro. Quanto menor o descanso da pastagem, maior é o número de ciclos de pastejo por ano (Tabela 2). O número de ciclos de pastejo é muito importante, quando se quer comparar sistemas de pastejo rotativo com diferentes períodos de descanso, visto que os dados sobre disponibilidade de forragem por área precisam ser ajustados para uma unidade de tempo comparável, como, por exemplo, quilogramas de matéria seca/ha/dia, de modo a evitar erros de interpretação devido ao período de descanso (Tabelas 4 e 5).

$\mathrm{Na}$ Tabela 3, são apresentados os dados médios de composição química e de digestibilidade in vitro da matéria seca (DIVMS) de amostras de extrusas de capim-elefante. Observa-se que os teores de MS foram relativamente baixos nos três períodos de descanso. Os menores valores foram observados nos meses de janeiro e maio. Entretanto, não houve diferença $(P>0,05)$ entre os tratamentos, no teor de matéria seca, em nenhum dos meses estudados. A razão para isso pode estar relacionada à contaminação das amostras com a saliva. A coleta de amostras através de extrusa provoca alta contaminação com saliva, resultando em baixos teores de matéria seca.

Houve diferença $(\mathrm{P}<0,05)$ entre tratamentos no teor de proteína bruta no mês de março. $\mathrm{O}$ tratamento com 45 dias de descanso apresentou o menor teor $(10,2 \%)$. Não houve diferença $(P>0,05)$ entre tratamentos no teor de proteína bruta nos outros meses estudados. VEIGA (1990), trabalhando com diferentes períodos de descanso em capim-elefante anão, também observou menor teor de proteína bruta nos períodos de descanso mais longos. Nota-se também que o teor de PB está abaixo dos valores esperados para o capim-elefante adubado com nitrogênio e manejado em sistema rotativo. A explicação para isso pode estar também relacionada com a forma de coleta de amostras.

Não houve diferença $(\mathrm{P}>0,05)$ entre tratamentos, nem entre meses do ano no teor de fibra em detergente neutro (FDN). Não há uma explicação aparente para a semelhança no teor de FDN nos diferentes períodos de descanso, visto que o esperado seria obter maior teor de FDN nos tratamentos com períodos de descanso maiores, como mostraram DERESZ e MOZZER (1994).

Houve diferença $(\mathrm{P}<0,05)$ entre tratamentos na DIVMS no mês de janeiro. O tratamento com 45 dias de descanso apresentou a menor digestibilidade $(50,8 \%)$. Não houve diferença a $5 \%$ entre tratamentos na DIVMS nos outros meses estudados. VEIGA (1990) também observou menor digestibilidade em capim-elefante anão nos períodos de descanso mais longos.

Tabela 2 - Ciclos completos de pastejo efetuados nos diferentes períodos de descanso em pastagem de capim-elefante

Table 2 - Number of complete grazing cycles across the range of grazing intervals studied on elephantgrass pasture Período de descanso (dias)

\begin{tabular}{lccc}
\hline & \multicolumn{3}{c}{$\begin{array}{c}\text { Período de descanso (dias) } \\
\text { Grazing }\end{array}$} \\
\cline { 2 - 4 } & 30 & 36 & 45 \\
\hline Ciclos de pastejo & 6,0 & 5,0 & 4,0 \\
Grazing cycles & & & \\
\hline
\end{tabular}


Rev. bras. zootec.

Tabela 3 - Teores médios de matéria seca (MS), proteína bruta (PB), fibra em detergente neutro (FDN) e digestibilidade in vitro da matéria seca (DIVMS) do capim-elefante em amostras de extrusa no ano de 1994

Table 3 - Average data for dry matter content (DM), crude protein (CP), neutral detergent fiber (NDF) and in vitro dry matter disappearance (IVDMD) of esophageal samples of elephantgrass collected in 1994

\begin{tabular}{|c|c|c|c|c|}
\hline \multirow{3}{*}{$\begin{array}{l}\text { Variável } \\
\text { Trait }\end{array}$} & \multicolumn{4}{|c|}{$\begin{array}{l}\text { Mês } \\
\text { Month }\end{array}$} \\
\hline & Janeiro & Março & Abril & Maio \\
\hline & January & March & April & May \\
\hline & \multicolumn{4}{|c|}{$\begin{array}{l}\text { Período de descanso (30 dias) } \\
\text { Grazing interval (30 days) }\end{array}$} \\
\hline MS (\%) & $11,7 \pm 0,3^{\mathrm{a}}$ & $12,9 \pm 0,2^{\mathrm{a}}$ & $12,7 \pm 0,3^{\mathrm{a}}$ & $11,3 \pm 0,4^{\mathrm{a}}$ \\
\hline \multicolumn{5}{|l|}{$D M$} \\
\hline $\mathrm{PB}(\%)$ & $13,0 \pm 0,3^{\mathrm{a}}$ & $14,5 \pm 0,9^{\mathrm{a}}$ & $9,8 \pm 1,6^{\mathrm{a}}$ & $13,4 \pm 0,5^{\mathrm{a}}$ \\
\hline FDN (\%) & $71,2 \pm 0,7^{\mathrm{a}}$ & $71,0 \pm 0,4^{\mathrm{a}}$ & $72,1 \pm 0,4^{\mathrm{a}}$ & $71,0 \pm 0,5^{\mathrm{a}}$ \\
\hline$N D F$ & & & & \\
\hline DIVMS (\%) & $65,9 \pm 1,2^{\mathrm{a}}$ & $63,0 \pm 1,3^{\mathrm{a}}$ & $60,8 \pm 0,1^{\mathrm{a}}$ & $50,0 \pm 4,5^{\mathrm{a}}$ \\
\hline \multicolumn{5}{|l|}{$I V D M D$} \\
\hline & \multicolumn{4}{|c|}{$\begin{array}{l}\text { Período de descanso (36 dias) } \\
\text { Grazing interval (36 days) }\end{array}$} \\
\hline MS (\%) & $11,5 \pm 0,4^{\mathrm{a}}$ & $12,6 \pm 0,2^{\mathrm{a}}$ & $12,2 \pm 0,7^{\mathrm{a}}$ & $10,9 \pm 0,2^{\mathrm{a}}$ \\
\hline \multirow{9}{*}{$\begin{array}{l}D M \\
\text { PB }(\%) \\
C P \\
\text { FDN }(\%) \\
N D F \\
\text { DIVMS }(\%) \\
\text { IVDMD } \\
\end{array}$} & & & & \\
\hline & $11,9 \pm 0,4^{\mathrm{a}}$ & $12,5 \pm 0,3^{\mathrm{a}}$ & - & $12,2 \pm 1,0^{\mathrm{a}}$ \\
\hline & & & & \\
\hline & $71,8 \pm 0,0^{\mathrm{a}}$ & $74,7 \pm 1,6^{\mathrm{a}}$ & $74,2 \pm 0,3^{\mathrm{a}}$ & $71,9 \pm 1,4^{\mathrm{a}}$ \\
\hline & & & & \\
\hline & $62,4 \pm 2,9^{\mathrm{a}}$ & $60,6 \pm 1,1^{\mathrm{a}}$ & $65,8 \pm 1,9^{\mathrm{a}}$ & $54,0 \pm 2,7^{\mathrm{a}}$ \\
\hline & \multirow{3}{*}{\multicolumn{4}{|c|}{$\begin{array}{l}\text { Período de descanso ( } 45 \text { dias) } \\
\text { Grazing interval (45 days) }\end{array}$}} \\
\hline & & & & \\
\hline & & & & \\
\hline MS (\%) & $12,6 \pm 0,1^{\mathrm{a}}$ & $12,6 \pm 0,7^{\mathrm{a}}$ & $13,0 \pm 0,3^{\mathrm{a}}$ & $10,5 \pm 0,1^{\mathrm{a}}$ \\
\hline \multicolumn{5}{|l|}{$D M$} \\
\hline PB (\%) & $11,1 \pm 0,6^{\mathrm{a}}$ & $10,2 \pm 0,8^{b}$ & - & $13,1 \pm 0,6^{\mathrm{a}}$ \\
\hline \multicolumn{5}{|l|}{$C P$} \\
\hline $\operatorname{FDN}(\%)$ & $71,9 \pm 0,1^{\mathrm{a}}$ & $73,0 \pm 0,3^{\mathrm{a}}$ & $72,5 \pm 0,6^{\mathrm{a}}$ & $70,9 \pm 0,4^{\mathrm{a}}$ \\
\hline \multicolumn{5}{|l|}{$N D F$} \\
\hline $\operatorname{DIVMS}(\%)$ & $50,8 \pm 2,0^{\mathrm{b}}$ & $62,0 \pm 0,6^{\mathrm{a}}$ & $60,4 \pm 0,6^{\mathrm{a}}$ & $67,6 \pm 1,9^{\mathrm{a}}$ \\
\hline
\end{tabular}

Médias seguidas de letras iguais na linha não diferem $(P>0,05)$.

Means within a row followed by the same letter are not different $(P>.05)$

Os resultados de composição química e da DIVMS das extrusas de capim-elefante mostram que esse sistema de coleta parece não ser o mais indicado. REEVES et al. (1996) também observaram que as amostras de forragem coletadas à mão, simulando o pastejo, foram mais representativas do valor nutritivo da forragem do que as amostras coletadas através da fístula esofageana, como se faz na Austrália. As razões para estas diferenças na composição química e valor nutritivo de amostras coletadas por meio destes dois métodos de amostragem deveriam ser melhor avaliadas.

Os dados sobre massa de forragem de capimelefante por hectare são apresentados na Tabela 4. Observa-se que houve um coeficiente de variação bastante alto para esta variável nos diferentes meses. O maior coeficiente de variação foi observado em janeiro $(32,8 \%)$ e o menor, em março $(8,9 \%)$. Houve diferença $(\mathrm{P}<0,05)$ entre tratamentos na massa de forragem por hectare no mês de março. $\mathrm{O}$ tratamento com 45 dias de descanso foi o que apresentou o menor valor (1979 kg de MS/ha). Não houve diferença $(\mathrm{P}>0,05)$ entre tratamentos nos outros meses. Observa-se que a massa de forragem por hectare tende a diminuir, à medida que os dias ficam mais curtos. Os menores valores foram observados nos meses de maio e junho, quando, além dos dias curtos, normalmente começa a faltar chuva e inicia-se a estação seca do ano. Por essa razão, nas condições em que foi realizado o experimento, geralmente, a partir do mês 
de maio, há necessidade de suplementação volumosa da pastagem. Observa-se que, nos tratamentos com 30 e 36 dias de descanso, o maior valor de massa de forragem por hectare encontrado foi no mês de março (2369 e $2666 \mathrm{~kg} / \mathrm{ha})$ e o menor valor (721 e $775 \mathrm{~kg} / \mathrm{ha}$ ), no mês de junho, respectivamente. Entretanto, no tratamento com 45 dias de descanso, o maior valor encontrado foi no mês de janeiro ( $2810 \mathrm{~kg} / \mathrm{ha})$ e o menor valor ( $962 \mathrm{~kg} / \mathrm{ha})$, também no mês de junho. SOARES et al. (1999) encontraram valores de massa de forragem de capim-elefante bastante semelhantes a estes.

Na Tabela 5, observa-se a disponibilidade média de matéria seca por vaca por dia. Para se obterem esses valores, usou-se a massa de forragem por hectare, dividida pelo número de piquetes $(11,13 \mathrm{ou}$ 16, dependendo do tratamento), o resultado dividido pela taxa de lotação $(4,5$ vacas/ha) e novamente dividido por três, que foi o período de ocupação dos piquetes. Por exemplo: $1850 \mathrm{~kg}$ de matéria seca/ha do tratamento de 30 dias de descanso de acordo com os cálculos abaixo:

$$
\frac{1.850}{11}=\frac{168,18}{4,5}=\frac{37,37}{3}=12,45 \mathrm{~kg} / \mathrm{vaca} / \mathrm{dia} .
$$

Tabela 4 - Estimativa da massa de forragem (kg MS/ha) em pastagem de capim-elefante submetido à diferentes períodos de descanso nos anos de $1993 / 94$

Table 4 - Herbage mass ( $\mathrm{kg} \mathrm{DM} / \mathrm{ha}$ ) of elephantgrass pasture rotationally grazed observing different grazing intervals in 1993/94

\begin{tabular}{lcccc}
\hline & \multicolumn{3}{c}{$\begin{array}{c}\text { Período de descanso (dias) } \\
\text { Grazing interval (days) }\end{array}$} & \\
\cline { 2 - 4 } $\begin{array}{l}\text { Mês } \\
\text { Month }\end{array}$ & 30 & 36 & 45 & CV \\
\hline $\begin{array}{l}\text { Nov. } \\
\text { Nov. }\end{array}$ & $1850^{\mathrm{a}}$ & $2229^{\mathrm{a}}$ & $2336^{\mathrm{a}}$ & 16,7 \\
$\begin{array}{l}\text { Dez. } \\
\text { Dec. }\end{array}$ & $1555^{\mathrm{a}}$ & $1732^{\mathrm{a}}$ & $2532^{\mathrm{a}}$ & 25,8 \\
Jan. & $1881^{\mathrm{a}}$ & $2039^{\mathrm{a}}$ & $2810^{\mathrm{a}}$ & 32,8 \\
$\begin{array}{l}\text { Jan. } \\
\text { Mar. }\end{array}$ & $2369^{\mathrm{a}}$ & $2666^{\mathrm{a}}$ & $1979^{\mathrm{b} *}$ & 8,9 \\
$\begin{array}{l}\text { Mar. } \\
\text { Abr. }\end{array}$ & $1835^{\mathrm{a}}$ & $1848^{\mathrm{a}}$ & $1948^{\mathrm{a}}$ & 25,9 \\
$\begin{array}{l}\text { Apr. } \\
\text { Maio }\end{array}$ & $1249^{\mathrm{a}}$ & $1514^{\mathrm{a}}$ & $1623^{\mathrm{a}}$ & 22,1 \\
$\begin{array}{l}\text { May } \\
\text { Jun. }\end{array}$ & $721^{\mathrm{a}}$ & $775^{\mathrm{a}}$ & $962^{\mathrm{a}}$ & 27,8 \\
$\begin{array}{l}\text { Jun. } \\
\text { Total }\end{array}$ & 11.460 & 12.803 & 14.190 & \\
\hline Medasseguidasdeletasiguasna & & & \\
\hline
\end{tabular}

Médias seguidas de letras iguais na linha não diferem entre si $(P>0,05)$. Means within a row followed by the same letter are not different $(P>05)$.
Não houve diferença $(\mathrm{P}>0,05)$ entre os tratamentos na disponibilidade média de matéria seca por vaca por dia nos diferentes meses do ano, com exceção do mês de março, em que o tratamento com 45 dias de descanso apresentou o menor valor (9,2 kg MS/vaca/ dia). Isso é reflexo da menor massa de forragem por hectare observada nesse tratamento (Tabela 4).

Observa-se que há tendência da disponibilidade de matéria seca por vaca por dia ser maior nos tratamentos com 30 e 36 dias de descanso nos diferentes meses do ano, com exceção dos meses de dezembro e janeiro, nos quais a disponibilidade é maior no tratamento com 45 dias de descanso (Tabela 5). Isso contraria os resultados obtidos por ANDRADE e GOMIDE (1971), os quais afirmam que o capim-elefante cortado a intervalos de 56 dias produzia mais matéria seca por hectare do que o capim-elefante cortado a cada intervalo de 28 dias. VELLEZ-SANTIAGO e ARROYO-AGUILU (1981) também não observaram diferenças na taxa de acúmulo diário de matéria seca de capim-elefante, quando compararam intervalos de corte de 30 ou 45 dias. Considerando que o capim-elefante não apresenta diferença na taxa de acúmulo diário de matéria seca nos intervalos de 30 ou 45 dias de descanso e a composição

Tabela 5 - Estimativa de disponibilidade média de matéria seca (kg/vaca.dia) em pastagem de capimelefante, nos diferentes períodos de descanso em 1993/94

Table 5 - Average dry matter availability (kg/cow.day) of elephantgrass pasture rotationally grazed observing different grazing intervals in 1993 and 1994

\begin{tabular}{lccc}
\hline & \multicolumn{3}{c}{$\begin{array}{c}\text { Período de descanso (dias) } \\
\text { Grazing interval (days) }\end{array}$} \\
\cline { 2 - 4 } $\begin{array}{l}\text { Mês } \\
\text { Month }\end{array}$ & 30 & 36 & 45 \\
\hline $\begin{array}{l}\text { Nov. } \\
\text { Nov. } \\
\text { Dez. } \\
\text { Dec. }\end{array}$ & $12,5 \pm 1,9^{\mathrm{a}}$ & $12,7 \pm 0,5^{\mathrm{a}}$ & $10,8 \pm 0,3^{\mathrm{a}}$ \\
Jan. & $10,5 \pm 1,0^{\mathrm{a}}$ & $9,9 \pm 1,3^{\mathrm{a}}$ & $11,7 \pm 1,3^{\mathrm{a}}$ \\
$\begin{array}{l}\text { Jan. } \\
\text { Mar. } \\
\text { Mar. }\end{array}$ & $12,7 \pm 1,2^{\mathrm{a}}$ & $11,6 \pm 1,7^{\mathrm{a}}$ & $13,0 \pm 2,3^{\mathrm{a}}$ \\
$\begin{array}{l}\text { Abr. } \\
\text { Apr. }\end{array}$ & $16,0 \pm 0,9^{\mathrm{a}}$ & $15,2 \pm 0,7^{\mathrm{a}}$ & $9,2 \pm 0,2^{\mathrm{b} *}$ \\
$\begin{array}{l}\text { Maio } \\
\text { May }\end{array}$ & $12,4 \pm 1,0^{\mathrm{a}}$ & $10,6 \pm 1,0^{\mathrm{a}}$ & $9,0 \pm 1,6^{\mathrm{a}}$ \\
Jun. & $8,4 \pm 1,3^{\mathrm{a}}$ & $8,6 \pm 1,0^{\mathrm{a}}$ & $7,5 \pm 0,3^{\mathrm{a}}$ \\
\hline
\end{tabular}

Médias seguidas de letras iguais na linha não diferem $(P>0,05)$. Means within a row followed by the same letter are not different $(P>05)$. 
Rev. bras. zootec.

química do capim-elefante varia bastante com o avanço da idade (BRITTO et al., 1965), o período de descanso de 30 dias seria o mais recomendável.

$\mathrm{Na}$ Tabela 6, são apresentadas as produções médias de leite, sem corrigir para $4 \%$ de gordura. Não houve interação entre período e tratamento. Observa-se que a produção diária média de leite no descanso de 30 dias foi de $11,7 \mathrm{~kg} / \mathrm{vaca}$, ao passo que aquela no descanso de 45 dias, de 10,5 kg/vaca. A diferença média na produção de leite foi de $1,2 \mathrm{~kg}$ entre o descanso de 30 e 45 dias. Nota-se que, a partir dos 30 dias do experimento, houve diferença na produção de leite entre estes dois tratamentos e esta manteve-se até o final do período experimental (Tabela 6).

Houve diferença $(\mathrm{P}<0,05)$ na produção de leite entre os tratamentos. As vacas do tratamento com descanso de 30 dias produziram mais que as dos tratamentos com descanso de 36 e 45 dias, sendo que entre estes não houve diferença $(\mathrm{P}>0,05)$. $\mathrm{O}$ coeficiente de variação nos dados de produção de leite para os três tratamentos foi de $14,7 \%$. A diferença média na produção de leite não corrigido para $4 \%$ de gordura (Tabela 6) e corrigido (Tabela 7) entre o tratamento com descanso de 30 e 45 dias foi em torno de $10 \%$ (Figura 1).

É importante salientar que é possível produzir, em média, durante um período de 198 dias, até $11,7 \mathrm{~kg}$ de

Tabela 6 - Produção média de leite (kg/vaca.dia) sem corrigir para $4 \%$ de gordura, em pastagem de capimelefante manejada com diferentes períodos de descanso em 1993/94

Table 6 - Average milk yield ( $\mathrm{kg} /$ cow.day) not $4 \%$ fat corrected on elephantgrass pasture rotationally grazed observing different grazing intervals in 1993/94

\begin{tabular}{|c|c|c|c|c|}
\hline \multirow[b]{2}{*}{$\begin{array}{l}\text { Período (dias) } \\
\text { Period (days) }\end{array}$} & \multicolumn{3}{|c|}{$\begin{array}{c}\text { Período de descanso (dias) } \\
\text { Grazing interval (days) } \\
\end{array}$} & \multirow{2}{*}{$\begin{array}{l}\text { Erro-padrão } \\
\text { da média } \\
\text { Standard error } \\
\text { of mean } \\
\end{array}$} \\
\hline & 30 & 36 & 45 & \\
\hline $1-30$ & 14,1 & 13,4 & 13,3 & \\
\hline $31-60$ & 13,3 & 12,1 & 12,5 & \\
\hline $61-90$ & 11,5 & 10,7 & 10,5 & \\
\hline $91-120$ & 11,7 & 10,7 & 10,3 & \\
\hline $121-150$ & 11,3 & 10,6 & 9,9 & \\
\hline $151-180$ & 10,4 & 10,0 & 8,6 & \\
\hline 181-198 & 9,9 & 9,5 & 8,5 & \\
\hline $\begin{array}{l}\text { Média } \\
\text { Mean }\end{array}$ & $11,7^{\mathrm{a}}$ & $11,0^{\mathrm{b}}$ & $10,5^{\mathrm{b} *}$ & 0,25 \\
\hline
\end{tabular}

* Médias seguidas de letras iguais na linha não diferem $(P>0,05)$.

${ }^{*}$ Means in the row with de same letter are not different $(P>.05)$. leite por vaca por dia em pastagem de capim-elefante adubada e manejada em sistema rotativo, com 30 dias de descanso e três dias de ocupação por piquete, com taxa de lotação de 4,5 vacas/ha, durante a estação chuvosa, sem suplementação com concentrado. Esse nível de produção de leite por vaca por dia, com essa taxa de lotação (4,5 vacas/ha), parece estar bem próximo do potencial de produção de leite de forrageiras tropicais bem manejadas e utilizando vacas mestiças Holandês x Zebu com potencial de produção de leite por lactação de $4000-4500 \mathrm{~kg}$. Resultados semelhantes foram publicados por COWAN et al. (1993) com vacas holandesas nas condições da Austrália.

Na Tabela 7, são apresentados os dados médios de produção de leite corrigido para 4\% e os dados de composição química do leite, em termos de porcentagem de gordura, proteína e de extrato seco total. Não houve diferença $(\mathrm{P}>0,05)$ na composição química do leite entre tratamentos para nenhuma das variáveis avaliadas. Na Tabela 8 e Figura 2, são apresentados os dados médios de ganho de peso e a variação média de peso vivo das vacas durante o período experimental. Não houve diferença $(P>0,05)$ entre tratamentos no ganho médio diário nos três períodos avaliados (Tabela 8). Observa-se que as vacas dos três tratamentos ganharam peso nos três períodos avaliados, o

Tabela 7 - Produção (kg/vaca.dia) e composição média de leite de vacas mestiças $\mathrm{H} \times \mathrm{Z}$, em pastagem de capim-elefante com diferentes períodos de descanso, durante a estação chuvosa de 1993/94

Table 7 - Average milk yield ( $\mathrm{kg} /$ cow.day) and composition of crossbred cows (Holstein x Zebu) managed on elephantgrass pasture rotationally grazed observing different grazing intervals in 1993/94

\begin{tabular}{|c|c|c|c|c|}
\hline \multirow[b]{2}{*}{$\begin{array}{l}\text { Período (dias) } \\
\text { Period (days) }\end{array}$} & \multicolumn{3}{|c|}{$\begin{array}{l}\text { Período de descanso (dias } \\
\text { Grazing interval (days) }\end{array}$} & \multirow{2}{*}{$\begin{array}{l}\text { is) } \\
\text { Erro-padrão } \\
\text { da média } \\
\text { Standard error } \\
\text { of mean }\end{array}$} \\
\hline & 30 & 36 & 45 & \\
\hline $\begin{array}{l}\text { Leite a } 4 \% \\
\text { Milk (4\% fat) }\end{array}$ & $11,4^{\mathrm{a}}$ & $10,6^{\mathrm{a}}$ & $10,3^{\mathrm{a}}$ & 0,4 \\
\hline $\begin{array}{l}\text { Gordura }(\%) \\
\text { Fat }\end{array}$ & $3,78^{a}$ & $3,71^{\mathrm{a}}$ & $3,85^{\mathrm{a}}$ & 0,13 \\
\hline $\begin{array}{l}\text { Proteína (\%) } \\
\text { Protein }\end{array}$ & $3,05^{\mathrm{a}}$ & $3,11^{\mathrm{a}}$ & $3,21^{\mathrm{a}}$ & 0,07 \\
\hline $\begin{array}{l}\text { Extrato seco } \\
\text { total }(\%) \\
\text { Total solids }\end{array}$ & $12,35^{\mathrm{a}}$ & $12,27^{\mathrm{a}}$ & $12,58^{\mathrm{a}}$ & 0,15 \\
\hline
\end{tabular}

Médias seguidas de letras iguais na linha não diferem $(P>0,05)$. Means within a row followed by the same letter are not different $(P>05)$. 


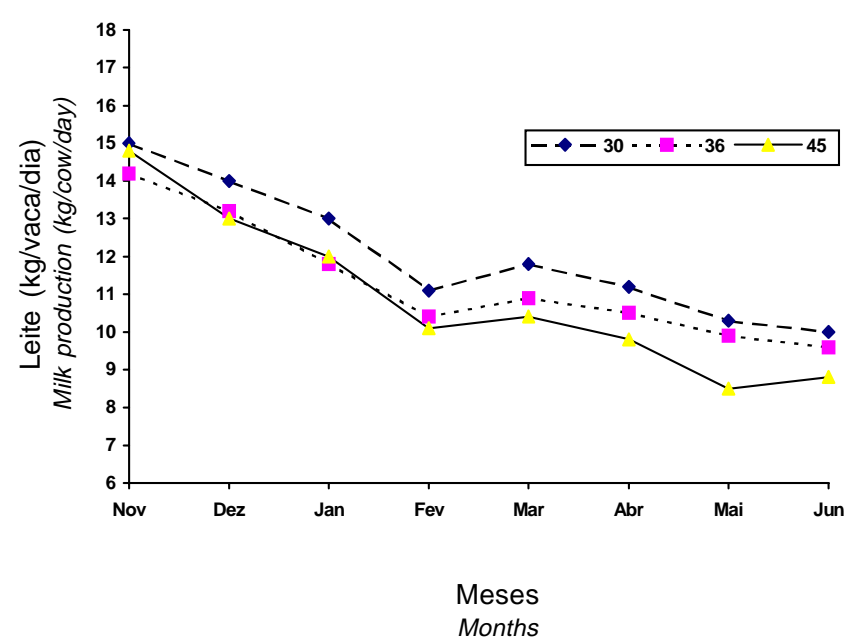

Figura 1 - Produção média de leite em pastagens de capimelefante com diferentes períodos de descanso, durante a estação das chuvas de 1993/94.

Figure 1 - Average milk yield on elephantgrass pasture rotationally grazed observing different grazing intervals in 1993/94.

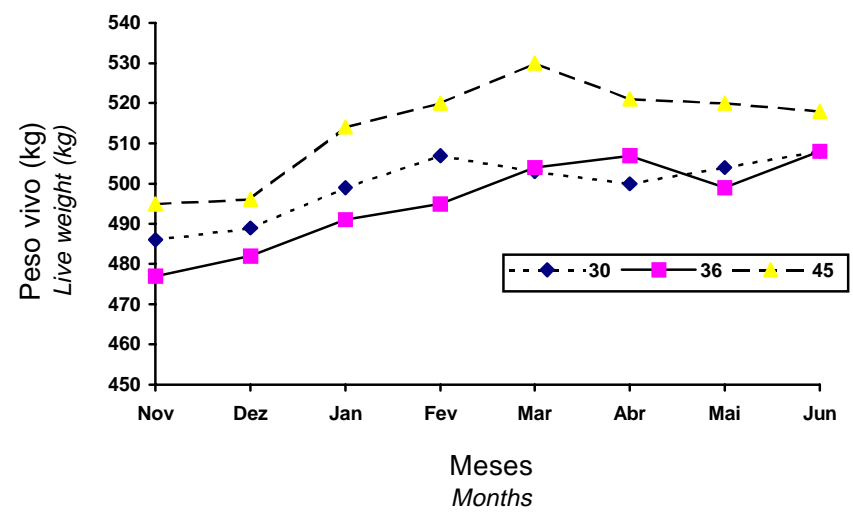

Figura 2 - Variação de peso vivo das vacas em pastagem de capim-elefante com diferentes períodos de descanso, durante a estação das chuvas de 1993/94.

Figure 2 - Live weight changes of cows on elephant grass pasture rotationally grazed observing different grazing intervals in 1993/94.

que indica que as produções médias de leite foram provenientes da forragem ingerida, e não da mobilização de reservas corporais. É bom salientar que, quando se considera todo o período experimental, a variação média de peso vivo foi muito pequena, ou seja, em torno de $114 \mathrm{~g}$ de ganho por dia (cerca de $23 \mathrm{~kg}$ de peso vivo).
Tabela 8 - Variação de peso vivo das vacas ( $\mathrm{g} / \mathrm{dia}$ ) manejadas em pastagem de capim-elefante em sistema rotativo, com diferentes períodos de descanso, durante a estação chuvosa de 1993/94

Table 8 - Liveweightchanges of cows (g/day) managed on elephant grass rotationally grazed observing different grazing intervals in 1993/94

\begin{tabular}{lcccc}
\hline \multicolumn{4}{c}{ intervals in 1993/94 } \\
& \multicolumn{4}{c}{$\begin{array}{c}\text { Período de descanso (dias) } \\
\text { Grazing interval (days) }\end{array}$} \\
\cline { 2 - 5 } $\begin{array}{l}\text { Período (dias) } \\
\text { Period (days) }\end{array}$ & 30 & 36 & 45 & $\begin{array}{c}\text { Erro Padrão } \\
\text { da Média } \\
\text { S.E.M. }\end{array}$ \\
\hline $1-10$ & & & & $291^{\mathrm{a}}$ \\
$10-29$ & $217^{\mathrm{a}}$ & $222^{\mathrm{a}}$ & 0,08 \\
$1-29$ & $65^{\mathrm{a}}$ & $130^{\mathrm{a}}$ & $34^{\mathrm{a}}$ & 0,06 \\
\hline & $114^{\mathrm{a}}$ & $160^{\mathrm{a}}$ & $116^{\mathrm{a}}$ & 0,04 \\
\hline
\end{tabular}

Médias seguidas de letras iguais na linha não diferem $(P>0,05)$. Means within a row followed by the same letter are not different $(P>05)$.

\section{Conclusões}

Na região da Zona da Mata de Minas Gerais, o capim-elefante deve ser manejado com 30 dias de descanso. Nessas condições, vacas mestiças Holandês x Zebu, com potencial de produção de leite de 4000 - $4500 \mathrm{~kg}$ por lactação, podem produzir na estação das chuvas, em média, 11,4 kg de leite por dia, sem suplementação com concentrado e sem perda de peso.

Não houve diferença na disponibilidade de matéria seca, quando o capim-elefante foi manejado em pastejo rotativo com período de descanso de 30, 36 e 45 dias.

Houve pequenas diferenças entre tratamentos, na composição química (MS, PB, e FDN) e na DIVMS da forragem de capim-elefante manejado em sistema rotativo, durante os meses de janeiro, março, abril e maio.

A disponibilidade de matéria seca diminuiu acentuadamente a partir do mês de abril, sendo os menores valores observados em junho.

\section{Referências Bibliográficas}

ALVIM, M.J., VILELA, D., CÓSER, A.C., LOPES, R.S. Efeitos de dois níveis de concentrado sobre a produção de leite de vacas da raça holandesa em pastagem de coast-cross. In: REUNIÃO ANUAL DA SOCIEDADE BRASILEIRA DE ZOOTECNIA, 33, 1996. Fortaleza, CE. Anais... Fortaleza: SBZ, 1996. p.172-173.

ANDRADE, I.F., GOMIDE, J.A. 1971. Curva de crescimento do capim-elefante (Pennisetum purpureum, Schum.) A-146. Revista Ceres, 18:431-447.

BRITTO, D.P.P.S., ARONOVICH, S., RIBEIRO, H. 1965. Comparação entre duas variedades de capim-elefante (Pennisetum purpureum, Schum.) e de seis diferentes espaços de tempo entre os cortes da planta. In: CONGRESSO INTERNACIONAL DE PASTAGENS, 1965, São Paulo. Anais... São Paulo: Secretaria da Agricultura, 1965. v.2, p.1683-1685. 
Rev. bras. zootec.

CARO-COSTAS, R., VICENTE-CHANDLER, J. 1969. Milk production with all-grass rations from steep, intensively, managed tropical pastures. J. Agric. University Puerto Rico, 53(4):251-258.

CARO-COSTAS, R., VICENTE-CHANDLER, J. 1974. Milk production of young Holstein cows fed only on grass pasture over three successive lactations. J. Agric. University Puerto Rico, 58(1):18-25.

COWAN, R.T., MOSS, R.J., KERR, D.V. 1993. Northern dairy feedbase 2001. 2. Summer Feeding Systems. Trop. Grassl., 27:150-161.

DERESZ, F. Manejo de pastagem de capim-elefante para produção de leite e carne. In: SIMPÓSIO SOBRE CAPIM-ELEFANTE, 2, 1994, Juiz de Fora. Anais... Coronel Pacheco, MG: EMBRAPA-CNPGL, 1994. p.116-137.

DERESZ, F., MOZZER, O.L. 1994. Produção de leite em pastagem de capim-elefante. In: CARVALHO, M.M., ALVIM, M.J., XAVIER, D.F. (Eds.) Capim-elefante: produção e utilização. Coronel Pacheco, MG: EMBRAPACNPGL. p.195-216.

DERESZ, F., CÓSER, A.C., MARTINS, C.E. et al. Utilização do capim-elefante (Pennisetum purpureum, Schum.) para a produção de leite. In: SIMPÓSIO BRASILEIRO DE FORRAGEIRAS E PASTAGENS, 1994, Campinas. Anais... Campinas, SP: CBNA, 1994. p.103-199.

GRANT, R.J., VAN SOEST, P.J., McDOWELL, R.E. et al. 1974. Intake, digestibility and metabolic loss of Napier grass by cattle and buffaloes when fed wilted, chopped and whole. J. Anim. Sci., 39(2):423-434.

HILLESHEIM, A. Fatores que afetam o consumo e perdas de capim-elefante (Pennisetum purpureum Schum.) sob pastejo. Piracicaba: ESALQ, 1987. 94p. Dissetação (Mestrado) Escola Superior de Agricultura "Luis de Queiroz", 1987.

HOLDEN, L.A., MULLER, L.D., FALES, S.L. 1994. Estimation of intake in high producing Holstein cows grazing grass pasture. J. Dairy Sci., 77(8):2332-2340.

HOLMES, C.W. Produção de leite a baixo custo em pastagens: uma análise do sistema neozelandês. In: CONGRESSO BRASILEIRO DE GADO LEITEIRO, 2, 1995, Piracicaba. Anais... Piracicaba: FEALQ, 1996. p.69-95.

KAISER, A.G., HAVILAH, E.J., CHOPPING, G.D., WALKER, R.G. 1993. Northern dairy feedbase 2001. 4. Feeding systems during winter and spring. Trop. Grassl., 27:180-211.

MATOS, L.L., DERESZ, F. Intensificação da produção de leite a pasto. In: CONGRESSO BRASILEIRO DE GADO LEITEIRO, 2, 1995, Piracicaba. Anais... Piracicaba: FEALQ, 1996. p.123-137.
REEVES, M., FULKERSON, W.F., KELLAWAY, R.C. et al. 1996. A comparison of three techniques to determine the herbage intake of dairy cows grazing kikuyu (Pennisetum clandestinum) pasture. Austr. J. Exper. Agric., 36:23-30.

SANTANA, J.R., PEREIRA, J.M., ARRUDA, N.G. 1989. Avaliação de cultivares de capim-elefante (Pennisetum purpureum, Schum.) no sul da Bahia. I Agrosistema Cacaueiro. R. Soc. Bras. Zootec., 18:273-283.

SOARES, J.P.G., AROEIRA, L.J.M., PEREIRA, O.G. et al. 1999. Capim-elefante (Pennisetum purpureum Schum.) sob duas doses de nitrogênio. Consumo e produção de leite. Rev. bras. zootec., 28:889-897.

VALLE, L.C.S., MOZZER, O.L., VILLAÇA, H.A. et al. Níveis de concentrado para vacas em lactação em pastagem de capimelefante (Pennisetum purpureum Schum.) no período das águas. In: REUNIÃO ANUAL DA SOCIEDADE BRASILEIRA DE ZOOTECNIA, 24, Brasília, DF. Anais... Brasília: SBZ, 1987. 56p.

VEIGA, J.B. Utilização do capim-elefante sob pastejo. In: SIMPÓSIO SOBRE CAPIM-ELEFANTE, 1, 1990, Coronel Pacheco: Anais... Coronel Pacheco: EMBRAPA-CNPGL, 1990. p.133-154.

VELLEZ-SANTIAGO, J., ARROYO-AGUILU, J.A. 1981. Effect of three harvest intervals on yield and nutritive value of seven Napier grass cultivars. J. Agric. University of Puerto Rico, 15:129-137.

VILELA, D., ALVIM, M.J., RESENDE, J.C., LOPES, R.S. 1996. Produção de leite em pastagem de coastcross (Cynodon dactylon L. Pers.) suplementada estrategicamente com concentrados. In: REUNIÃO ANUAL DA SOCIEDADE BRASILEIRA DE ZOOTECNIA, 33, 1996, Fortaleza, CE. Anais... Fortaleza: SBZ, 1996. v.3, p.169-171.

WERNER, J.C., LIMA, F.P., MARTINELLI, D. 1966. Estudos de três diferentes alturas de cortes em capim-elefante napier. Bol. Ind. Anim., 23:161-168.

Recebido em: 12/05/99

Aceito em: 09/11/00 